\title{
Acromegaly with empty sella syndrome
}

\author{
Reyna Daya1,2 ${ }^{\mathbb{D}}$, Faheem Seedat ${ }^{1,2}$, Khushica Purbhoo ${ }^{3}$, Saajidah Bulbulia1,2 $\mathbb{D}$ and Zaheer Bayat ${ }^{1,2}$
}

1Division of Endocrinology and Metabolism, Department of Internal Medicine, Helen Joseph Hospital, Rossmore, Johannesburg, South Africa, ${ }^{2}$ Division of Endocrinology and Metabolism, Department of Internal Medicine, Faculty of Health Sciences, School of Clinical Medicine, University of the Witwatersrand, Johannesburg, South Africa, and 3Department of Nuclear Medicine and Molecular Imaging, Chris Hani Baragwanath Academic Hospital and Charlotte Maxeke Johannesburg Academic Hospital, Faculty of Health Sciences, University of Witwatersrand, Johannesburg, South Africa

Correspondence should be addressed to F Seedat

Email

seedat.faheem@gmail.com

\section{Summary}

Acromegaly is a rare, chronic progressive disorder with characteristic clinical features caused by persistent hypersecretion of growth hormone (GH), mostly from a pituitary adenoma (95\%). Occasionally, ectopic production of GH or growth hormone-releasing hormone (GHRH) with resultant GH hypersecretion may lead to acromegaly. Sometimes localizing the source of GH hypersecretion may prove difficult. Rarely, acromegaly has been found in patients with an empty sella (ES) secondary to prior pituitary radiation and/or surgery. However, acromegaly in patients with primary empty sella (PES) is exceeding rarely and has only been described in a few cases. We describe a 47-year-old male who presented with overt features of acromegaly (macroglossia, prognathism, increased hand and feet size). Biochemically, both the serum $\mathrm{GH}(21.6 \mu \mathrm{g} / \mathrm{L})$ and insulin-like growth factor $1(635 \mu \mathrm{g} / \mathrm{L})$ were elevated. In addition, there was a paradoxical elevation of GH following a $75 \mathrm{~g}$ oral glucose load. Pituitary MRI demonstrated an ES. In order to exclude an ectopic source of GH hypersecretion, further biochemical tests and imaging were done, which were unremarkable. Notably, increased uptake in the sella turcica on the ${ }^{68}$ Gallium DOTATATE PET/CT confirmed the ES as the likely source of GH secretion. As no overt lesion was noted, medical treatment (octreotide acetate) was initiated with a good clinical and biochemical response. At his 3 month follow-up, he reported an improvement in symptoms (fatigue and headache), however he still complained of low libido. Due to a persistently low testosterone level at follow-up, a long-acting testosterone was initiated. His GH level normalised, and IGF-1 has significantly reduced.

\section{Learning points:}

- The commonest cause of acromegaly is due to GH hypersecretion from pituitary adenomas (95\%).

- Acromegaly has rarely been found in patients with ES.

- It is important to exclude a past history suggestive of pituitary apoplexy.

- Extra-pituitary source of GH such as ectopic production of GHRH with resultant GH hypersecretion needs to be excluded.

- In such cases, since there is no resectable mass, medical therapy is the primary treatment option.

\section{Background}

Acromegaly is a rare pituitary disorder caused by growth hormone GH hypersecretion. The estimated prevalence is 30-70 individuals per million with an annual incidence of 3-4 cases per million (1). Circulating GH stimulates insulin-like growth factor 1 (IGF-1) production by the liver and systemic tissues, which mediates the somatic and metabolic effects of GH.

Hypersecretion of GH leads to excessive production of IGF-1 and hence acromegaly, a multisystem disease. The characteristic features include (in descending order 
of frequency) acral and facial changes, hyperhidrosis, headaches, paraesthesia, sexual dysfunction, hypertension, goiter, and rarely, visual field defects (2). Acromegaly is associated with multiple co-morbidities including (but not limited to) hypertension, cardiac failure, arrhythmias, obstructive sleep apnoea, type 2 diabetes mellitus, arthritis, and carpal tunnel syndrome. If left untreated, mortality associated with cardiovascular, cerebrovascular, and pulmonary dysfunction increases, and life expectancy is reduced by up to $30 \%(3,4)$.

The aetiology of acromegaly is due to $\mathrm{GH}$ hypersecretion from pituitary adenomas (95\%) and in rare cases, ectopic production of $\mathrm{GH}$ or growth hormone releasing hormone (GHRH) with resultant GH hypersecretion. Localizing the source of $\mathrm{GH}$ hypersecretion may prove difficult sometimes. Rarely, acromegaly has been found in patients with an empty sella (ES) secondary to prior pituitary radiation and/or surgery $(5,6,7)$. However, this has rarely been described in patients with a primary empty sella (PES) $(8,9,10)$.

We describe a case of a 47-year-old male who presented with clinical and biochemical features of acromegaly, who had an ES on pituitary MRI.

\section{Case presentation}

A 47-year-old unemployed African man presented to the endocrine clinic with a history of fatigue, headaches, and low libido. He reported no nausea, vomiting, or any change in vision. There was no other significant medical, family, or drug history. In addition, he had no prior history of pituitary imaging, surgery, or head and neck radiation. Upon further questioning, he admitted to coarsening of his facial features which were also noted in comparison to photographs of him at a younger age. Furthermore, he reported difficulties with putting on his wedding ring for the last 5 years and having to purchase new shoes (US size 11) as his previous pairs (US size 9) no longer fit him.

On examination, he was $1.88 \mathrm{~m}$ (74 inches) tall, weighed $106 \mathrm{~kg}$ with a BMI of $30 \mathrm{~kg} / \mathrm{m}^{2}$. Blood pressure, heart rate, respiratory rate, and temperature were all normal. The patient had an acromegalic appearance with coarse facial features, a big nose, prognathism, malocclusion of his teeth, enlarged tongue and lips (Figs 1 and 2). His hands were large and spade-like, with thickened sausage-shaped fingers (Fig. 3), with oily and sweaty skin. Systemic cardio-respiratory and abdominal examinations were otherwise unremarkable. He had no palpable goitre and visual fields, visual acuity and fundoscopy were normal.

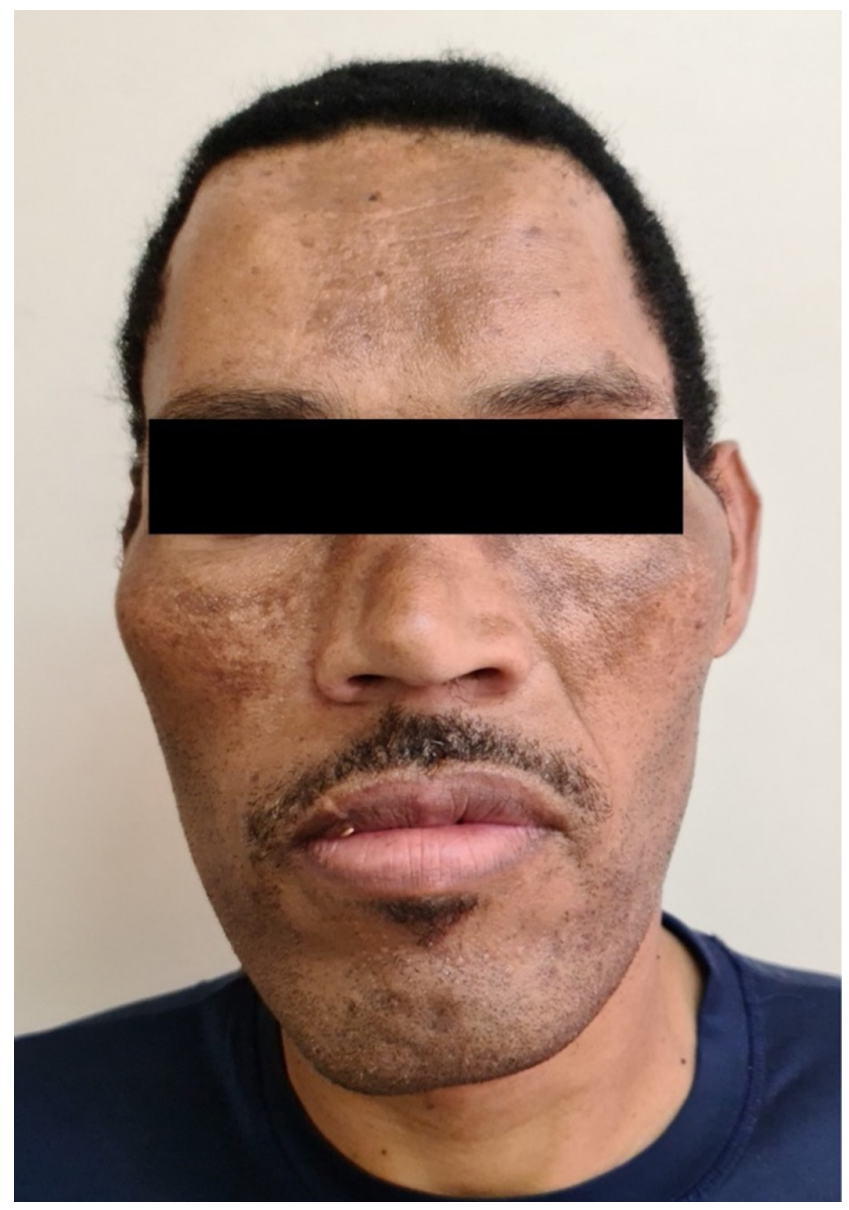

Figure 1

Face showing coarse facial features, prominent brow, big nose, and enlarged thick lips.

\section{Investigation}

Biochemical investigations highlighted elevated GH and IGF-1 levels (Table 1). There was a paradoxical elevation of GH following a $75 \mathrm{~g}$ oral glucose load (Table 2). The gonadal axis revealed a low testosterone level with inappropriately normal follicle-stimulating hormone (FSH) and luteinizing hormone (LH) levels. Prolactin levels (post-PEG precipitation) were elevated but were below $100 \mu \mathrm{g} / \mathrm{L}$. The remainder of the pituitary panel investigations (adrenocorticotropic hormone (ACTH), cortisol, tetraiodothyronine (T4), and thyroid-stimulating hormone (TSH)) was normal (Table 1).

MRI of the brain revealed cerebrospinal fluid intensity signal in the sella confines with enlargement and remodelling of bony sella turcica, in keeping with an ES (Figs. 4, 5, 6). In order to exclude an ectopic source of the GH hypersecretion, further biochemical (plasma chromogranin A and calcitonin, 24-h urine metanephrines 


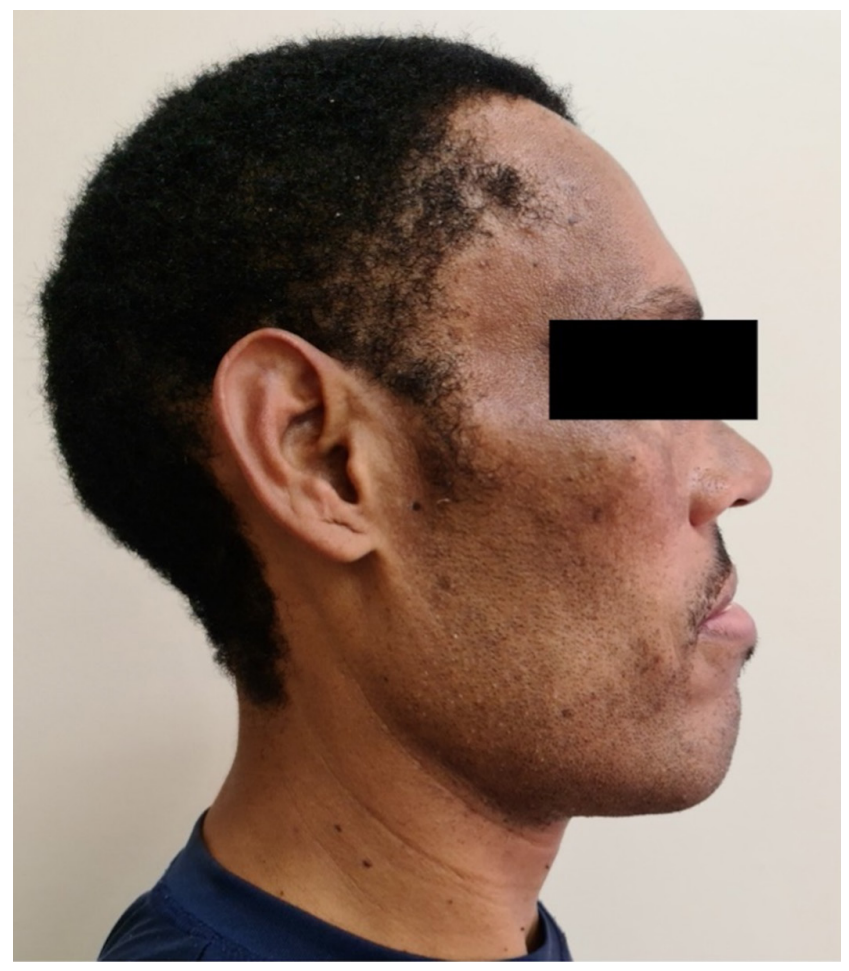

Figure 2

Side view highlighting prognathism and large ears.

and normetanephrines) and imaging (neck, chest, and abdominal CT) tests were performed, all were unremarkable.

Whole-body ${ }^{68}$ Gallium DOTATATE PET/CT revealed uptake in the pituitary gland in keeping with physiological somatostatin expression within the sella turcica (Fig. 7).

Based on the biochemical and radiological findings, a diagnosis of acromegaly with an ES was made.

\section{Treatment}

The patient was started on medical therapy. A monthly long-acting somatostatin analogue (octreotide acetate $20 \mathrm{mg}$ i.m. injection) was initiated.

\section{Outcome and follow-up}

At his 3 month follow-up, he reported an improvement in symptoms (fatigue and headache), however he still complained of low libido. Due to a persistently low testosterone level at follow-up, a long-acting testosterone therapy (250 mg testosterone undecanoate) was started. His GH level normalized, and IGF-1 has significantly reduced (Table 1). In the absence of therapy, the prolactin level has improved.

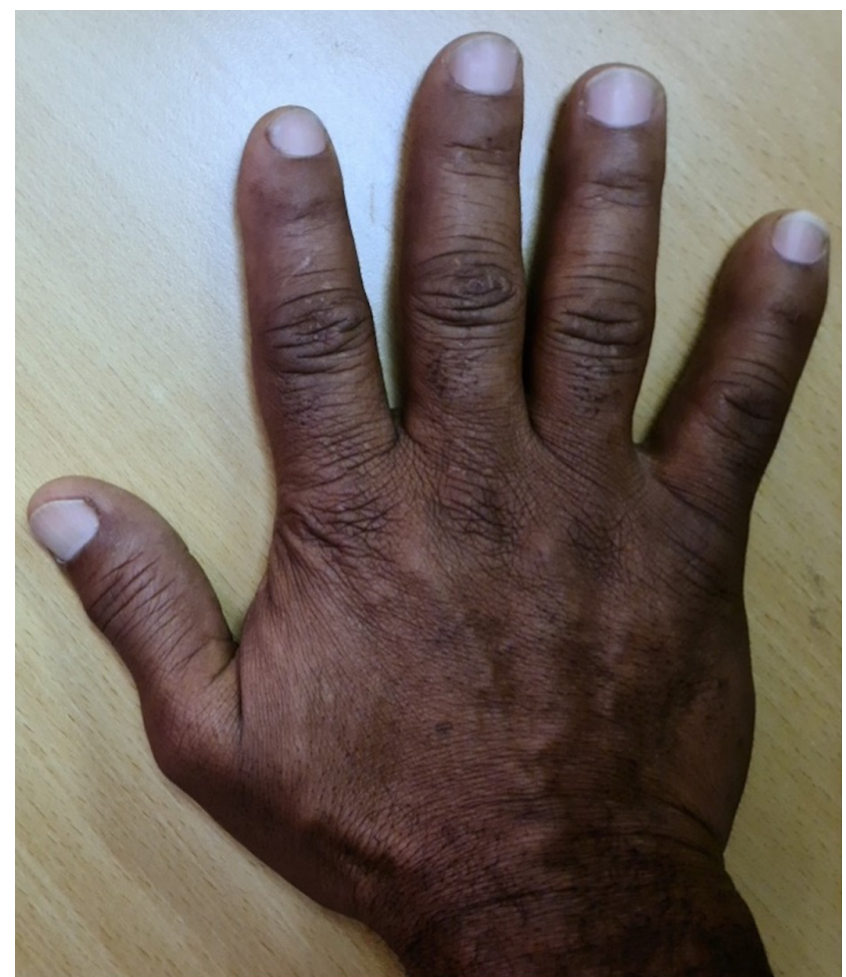

Figure 3

Acral enlargement of the hand highlighting large spade-like hand with thick sausage like fingers.

The patient will continue to be monitored and his biochemistry and imaging will be repeated at his 6-month follow-up appointment.

\section{Discussion}

ES refers to a neuro-radiological entity characterized by a cerebrospinal fluid-filled sella turcica, with the normal pituitary gland compressed to the rim of the fossa (11). ES may be classified as primary (PES) or secondary (SES) based on the aetiology. PES is rare and occurs in individuals with no prior pituitary disease. Its aetiology is unclear but has been linked to incompetence or absence of the diaphragma sella, chronic intracranial hypertension, or temporary expansion followed by the regression of the pituitary gland (12). SES is related to pathological processes within the sella region; such as pituitary atrophy after medical treatment, surgery, radiotherapy, apoplexy, postpartum pituitary necrosis, pituitary infections, autoimmune diseases of the pituitary, malignancies, and trauma (13).

Contrary to conventional belief, ES is frequently associated with a variety of neurological and endocrine disturbances. Most patients with PES syndrome are found to have a normal pituitary function, while about $30 \%$ have 
Table 1 Summary of biochemical results.

\begin{tabular}{l}
\hline Variable \\
\hline Growth hormone (GH) \\
Insulin-like growth factor (IGF-1) \\
Post PEG prolactin \\
Luteinising hormone (LH) \\
Follicle-stimulating hormone (FSH) \\
Testosterone \\
Thyroid-stimulating hormone (TSH) \\
Tetraiodothyronine (T4) \\
Adrenocorticotropic hormone (ACTH) \\
Cortisol \\
Chromogranin A \\
Calcitonin \\
24-h urine metanephrines \\
Normetanephrine:creatinine \\
24-h urine metanephrines \\
Metanephrine:creatinine
\end{tabular}

\begin{tabular}{c}
\hline Result \\
\hline $\mathbf{2 1 . 6}$ \\
$\mathbf{6 3 5}$ \\
$\mathbf{3 5 . 0}$ \\
2.6 \\
10.9 \\
$\mathbf{5 . 2}$ \\
0.56 \\
17.0 \\
4.3 \\
173 \\
56.9 \\
2.1 \\
1187 \\
102.87 \\
731 \\
71.14
\end{tabular}

\begin{tabular}{c}
\hline month follow-up \\
\hline 2.0 \\
$\mathbf{2 7 5}$ \\
$\mathbf{2 1 . 3}$ \\
1.3 \\
9.8 \\
$\mathbf{8 . 5}$ \\
1.79 \\
13.5 \\
3.6 \\
214 \\
\end{tabular}

\begin{tabular}{l}
\hline Reference range \\
\hline$<0.03-2.47 \mu \mathrm{g} / \mathrm{L}$ \\
$53.0-215 \mu \mathrm{g} / \mathrm{L}$ \\
$3.0-11.6 \mu \mathrm{g} / \mathrm{L}$ \\
$1.7-8.6 \mathrm{IU} / \mathrm{L}$ \\
$1.5-12.4 \mathrm{IU} / \mathrm{L}$ \\
$8.8-27.9 \mathrm{nmol} / \mathrm{L}$ \\
$0.35-4.95 \mathrm{mIU} / \mathrm{L}$ \\
$9.1-19.0 \mathrm{pmol} / \mathrm{L}$ \\
$1.6-13.9 \mathrm{pmol} / \mathrm{L}$ \\
$133-537 \mathrm{nmol} / \mathrm{L}$ \\
$0-84.7 \mathrm{ng} / \mathrm{mL}$ \\
$<11.8 \mathrm{ng} / \mathrm{L}$ \\
$480-2424 \mathrm{nmol} / 24 \mathrm{~h}$ \\
$28-158 \mathrm{nmol} / \mathrm{mmol}$ creatinine \\
$264-1729 \mathrm{nmol} / 24 \mathrm{~h}$ \\
$15-89 \mathrm{nmol} / \mathrm{mmol}$ creatinine
\end{tabular}

Bold values are to highlight the abnormal parameters

varying degrees of hypopituitarism (14). Acromegaly has occasionally been found in patients with SES following prior pituitary irradiation and/or surgery. However, acromegaly in patients with PES is exceedingly rare and limited to a handful of case reports and a few retrospective studies. In a single retrospective study of 76 patients with ES, only 3 patients were diagnosed with acromegaly $(9,15,16,17$, 18). Following this, three retrospective studies conducted between 2004 and 2017 reported acromegaly with ES in $20.3 \%$ (19), $22 \%$ (20), and $15.4 \%$ (21) of cases, respectively.

The most commonly held hypothesis concerning the aetiology of acromegaly with PES includes an undetectable microadenoma in the pituitary tissue lining the sella as the source of excess GH production or silent infarction of a pituitary mass or adenoma with the development of a partial or total ES (22). Other hypotheses cite downward growth of an adenoma, enlargement of the sella and sella floor remodelling through compression or direct effect on the bone from elevated GH and IGF-1 levels $(19,20)$.

Our patient has an ES without a history of a prior pituitary procedure or head and neck radiation. As such, we postulate he most likely had a prior pituitary microadenoma, which underwent asymptomatic and silent infarction and

Table $275 \mathrm{~g}$ oral acromegaly glucose tolerance test.

\begin{tabular}{l}
\hline \\
\hline Reference range (min) \\
0 \\
30 \\
60 \\
90 \\
120 \\
\hline
\end{tabular}

\begin{tabular}{|c|c|}
\hline Glucose (mmol/L) & Growth hormone $(\mu \mathrm{g} / \mathrm{L})$ \\
\hline & $<0.03-2.47$ \\
\hline 6.7 & 8.7 \\
\hline 9.1 & 8.2 \\
\hline 9.1 & 7.8 \\
\hline 7.2 & 7.7 \\
\hline 4.4 & 9.4 \\
\hline
\end{tabular}

subsequent development of a total ES. It is evident that the infarct did not totally ablate the hyperfunctioning tissue in this patient, as demonstrated by elevated, non-suppressible GH levels and uptake shown in the pituitary fossa on the ${ }^{68}$ Gallium DOTATATE PET/CT scan.

Pituitary adenomas are associated with headaches, but so too is ES. A number of patients with PES present with headaches, which are described as lateral, persistent, and datable for years (23). Our patient's presentation of headache may be multifactorial including a possible initial pituitary adenoma, an ES, or directly from an elevated GH level.

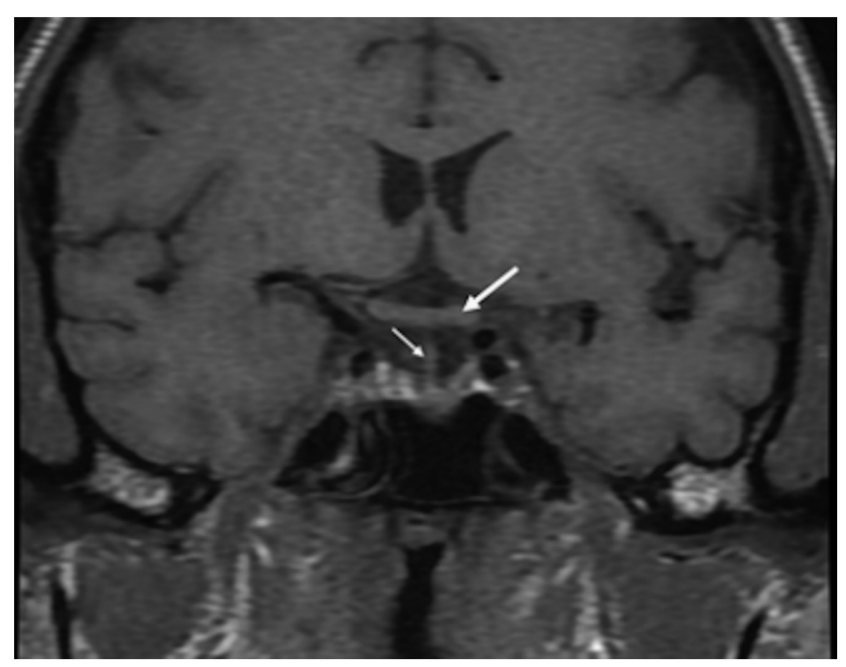

Figure 4

Coronal T1 weighted cut demonstrating empty sella with optic chiasm (large arrow) and pituitary stalk (small arrow) extending to the residual thinned and flattened pituitary tissue visible along the base of the sella. 


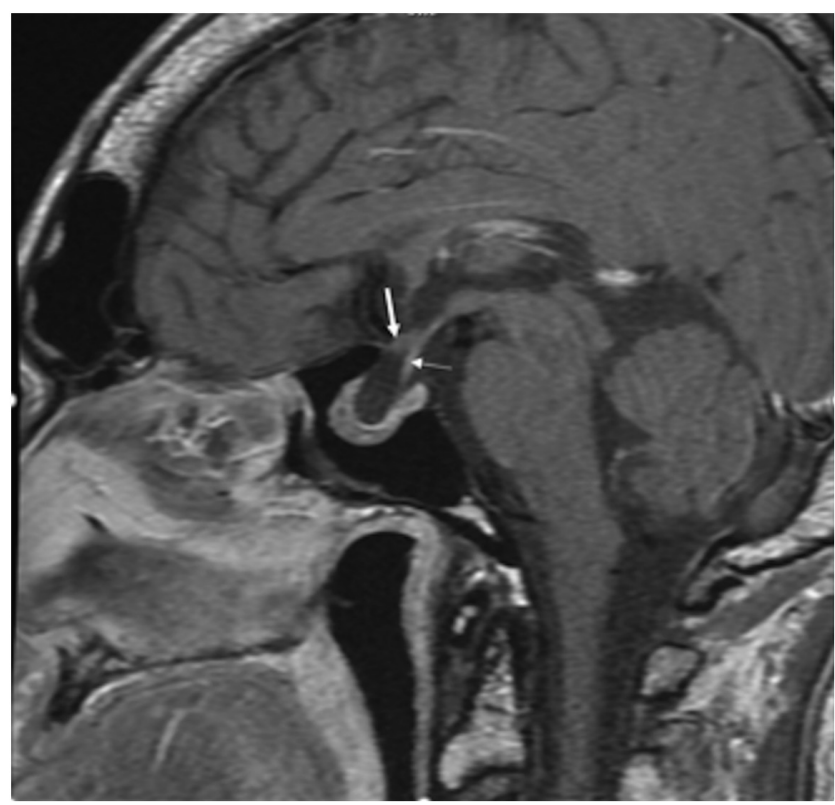

\section{Figure 5}

Sagittal T1 weighted cut demonstrating empty sella with optic chiasm (large arrow) and pituitary stalk (small arrow) extending to the residual thinned and flattened pituitary tissue visible along the base of the sella.

Ectopic acromegaly occurs due to the secretion of GHRH or rarely GH from extra-pituitary tumors (24). When compared to a pituitary cause of acromegaly where GHRH levels may be normal or more often suppressed, in the case of ectopic GHRH secretion, serum GHRH levels are raised $(25,26,27)$. Typically, ectopic tumours secreting GHRH or GH are located within the chest or abdominal cavity and are easily detectable by conventional radiological techniques

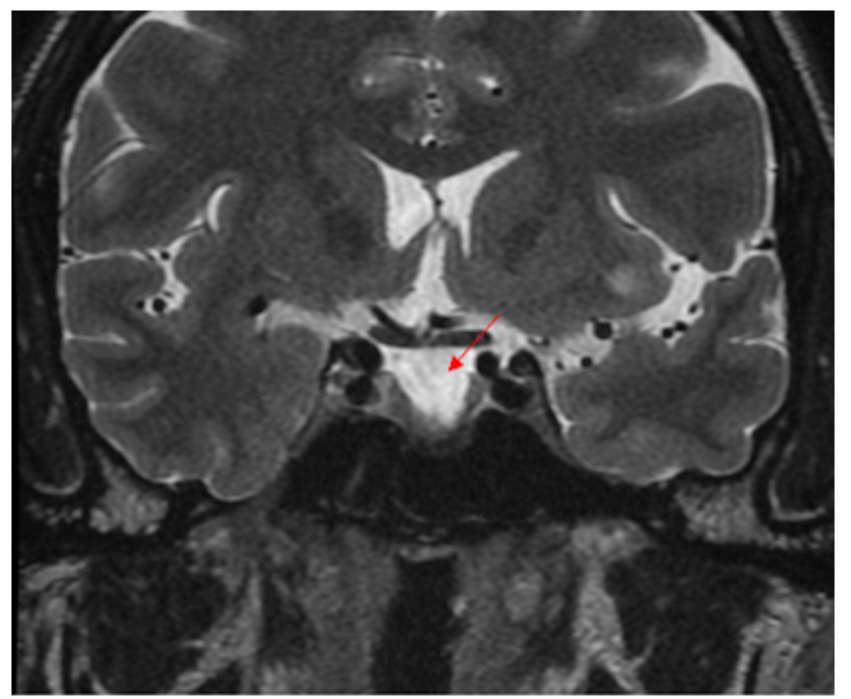

Figure 6

Coronal $\mathrm{T} 2$ weighted cut demonstrating empty sella (arrow).

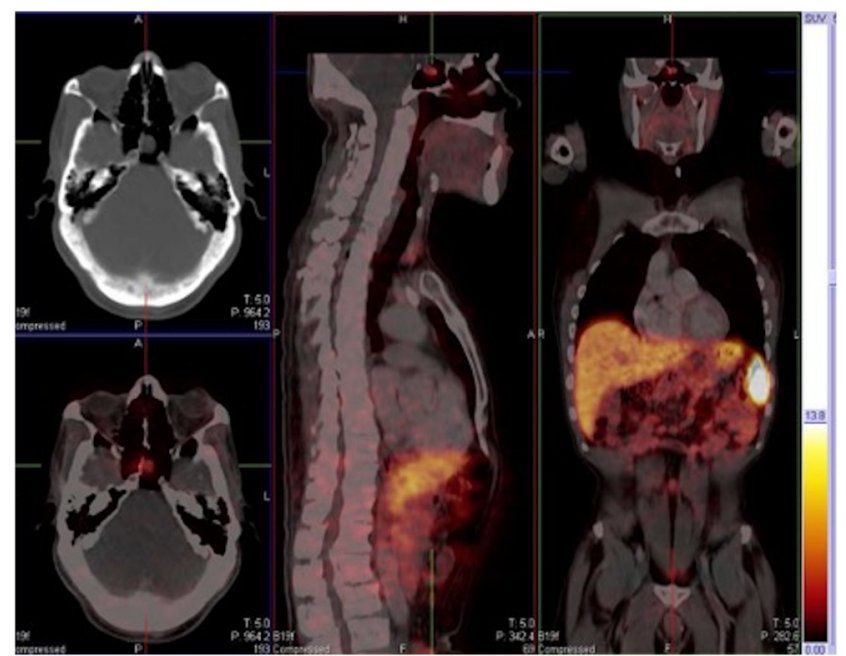

Figure 7

${ }^{68}$ Gallium DOTATATE PET/CT showing receptor activity in the pituitary gland due to physiological somatostatin receptor expression.

(CT or MRI). As these tumours suppress somatostatin receptors, they may also be detected using somatostatin scintigraphy, which is particularly useful in the detection of smaller tumours, or metastatic disease (27).

In our case, due to the normal neck, chest, and abdominal CT and as the ${ }^{68}$ Gallium DOTATATE PET/CT scan which did not demonstrate extra-pituitary uptake, it is unlikely an ectopic source of GHRH or GH secretion was present.

Since no resectable pituitary mass is present, medical management with somatostatin analogues remains the only viable treatment option that may be offered to patients with acromegaly and an ES.

\section{Conclusion}

Whilst the underlying mechanism remains unclear, the co-existence of acromegaly and ES is not rare. However, PES with acromegaly is exceedingly rare. This case demonstrates that despite ES syndrome, the source of GH hypersecretion can still be from the pituitary fossa. In such cases, an undetectable microadenoma in the pituitary tissue lining the sella is thought to be the source of excess GH production.

\section{Declaration of interest}

The authors declare that there is no conflict of interest that could be perceived as prejudicing the impartiality of the research reported.

\section{Funding}

This research did not receive any specific grant from any funding agency in the public, commercial or not-for-profit sector. 


\section{Patient consent}

Written informed consent was obtained from the patient for submission of the publication and accompanying images.

\section{Author contribution statement}

R Daya wrote the first draft of the manuscript. R Daya, F Seedat, S Bulbulia, K Purbhoo, and Z Bayat edited the submitted manuscript. Z Bayat supervised the overall preparation of the manuscript. All authors reviewed the final manuscript and reviewed it for publication.

\section{References}

1 Katznelson L, Laws Jr ER, Melmed S, Molitch ME, Murad MH, Utz A, Wass JA \& Endocrine Society. Acromegaly: an Endocrine Society clinical practice guideline. Journal of Clinical Endocrinology and Metabolism 201499 3933-3951. (https://doi.org/10.1210/jc.2014-2700)

2 Molitch ME. Clinical manifestations of acromegaly. Endocrinology and Metabolism Clinics of North America 199221 597-614. (https://doi. org/10.1016/S0889-8529(18)30204-4)

3 Melmed S. Acromegaly pathogenesis and treatment. Journal of Clinical Investigation $20091193189-3202$. (https://doi.org/10.1172/JCI39375)

4 Rajasoorya C, Holdaway IM, Wrightson P, Scott DJ \& Ibbertson HK. Determinants of clinical outcome and survival in acromegaly. Clinical Endocrinology 199441 95-102. (https://doi. org/10.1111/j.1365-2265.1994.tb03789.x)

5 Padniewski J, Pluhm R, Domatova M, Rashid U \& Horani M. SAT-469 empty Sella making big changes: a case of acromegaly and empty Sella syndrome. Journal of the Endocrine Society 20193 (Supplement_1) SAT469. (https://doi.org/10.1210/js.2019-SAT-469)

6 Kim DJ, Seo YJ, Kim NH, Chung HS, Eun CR, Choi HJ, Kim HS Yang SJ, Park J, Yoo HJ, et al. Two cases of acromegaly with empty Sella syndrome treated by long-acting release octreotide. Journal of Korean Endocrine Society 200722 135-141. (https://doi.org/10.3803/ jkes.2007.22.2.135)

7 Pappa D, Thoda P, Rizoulis A, Gountios I, Kapsalaki E \& Bargiota A, Eds. Patient with empty sella and clinical features of acromegaly. In 19th European Congress of Endocrinology. BioScientifica, 201749. (https://doi. org/10.1530/endoabs.49.EP861)

8 Molitch ME, Hieshima GB, Marcovitz S, Jackson IM \& Wolpert S. Coexisting primary empty sella syndrome and acromegaly. Clinical Endocrinology 19777 261-263. (https://doi. org/10.1111/j.1365-2265.1977.tb01323.x)

9 Hekimsoy Z, Yünten N \& Sivrioglu S. Coexisting acromegaly and primary empty sella syndrome. Neuro Endocrinology Letters 200425 307-309.

10 Shumy F \& Kahhar MA. Acromegaly in primary empty Sella. Journal of Medicine 200910 119-120. (https://doi.org/10.3329/jom.v10i2.2827)

11 Del Monte P, Foppiani L, Cafferata C, Marugo A \& Bernasconi D. Primary 'empty sella' in adults: endocrine findings. Endocrine Journal 200653 803-809. (https://doi.org/10.1507/endocrj.k06-024)

12 Chiloiro S, Giampietro A, Bianchi A, Tartaglione T, Capobianco A, Anile C \& De Marinis L. Diagnosis of endocrine disease: primary empty sella: a comprehensive review. European Journal of Endocrinology 2017177 R275-R285. (https://doi.org/10.1530/EJE-17-0505)

13 Miljic D, Pekic S \& Popovic V. Empty sella. In: Feingold KR, Anawalt B, Boyce A, et al., editors. Endotext [Internet]. MA, USA: MDText. com, Inc.; 2000. (available at: https://www.ncbi.nlm.nih.gov/books/ NBK532084.

14 Neelon FA, Goree JA \& Lebovitz HE. The primary empty sella: clinical and radiographic characteristics and endocrine function. Medicine 197352 73-92. (https://doi.org/10.1097/00005792-197301000-00004)

15 Gallardo E, Schächter D, Caceres E, Becker P, Colin E, Martinez C \& Henríquez C. The empty sella: results of treatment in 76 successive cases and high frequency of endocrine and neurological disturbances. Clinical Endocrinology 199237 529-533. (https://doi. org/10.1111/j.1365-2265.1992.tb01484.x)

16 Hong JF, Ding XH \& Wang SS. Coexistence of ectopic pituitary adenoma and empty sella in a patient with acromegaly: a case report and review of literature. Neurology India 201260 304-306. (https://doi. org/10.4103/0028-3886.98517)

17 Arzamendi AE, Shahlaie K, Latchaw RE, Lechpammer M \& Arzumanyan H. Ectopic acromegaly arising from a pituitary adenoma within the bony intersphenoid septum of a patient with empty sella syndrome. Journal of Neurological Surgery Reports 201677 e113-e117. (https://doi.org/10.1055/s-0036-1585091)

$18 \mathrm{Su}$ H, Zhou J, Bao YQ, Mo YF, Zhang WT, Zhao JG, Ma XJ \& Jia WP. Primary empty sella associated with pituitary adenoma diagnosed by inferior petrosal sinus blood sampling. Chinese Medical Journal 2015 128 567-568. (https://doi.org/10.4103/0366-6999.151123)

19 Liu W, Zhou H, Neidert MC, Schmid C, Bernays RL, Ni M, Zhou D, Jia W \& Jia G. Growth hormone secreting pituitary microadenomas and empty sella - an under-recognized association? Clinical Neurology and Neurosurgery 2014126 18-23. (https://doi.org/10.1016/j. clineuro.2014.08.012)

20 Bier G, Hempel JM, Grimm F, Ernemann U, Bender B \& Honegger J. Quantification of specific growth patterns and frequency of the empty sella phenomenon in growth hormone-secreting pituitary adenomas. European Journal of Radiology 2018104 79-86. (https://doi. org/10.1016/j.ejrad.2018.05.009)

21 Sasagawa Y, Hayashi Y, Tachibana O, Oishi M, Fukui I, Iizuka H \& Nakada M. Clinical characteristics of acromegalic patients with empty sella and their outcomes following transsphenoidal surgery. Pituitary 201720 403-408. (https://doi.org/10.1007/s11102-017-0798-6)

22 Jameson JL. Harrison's Principles of Internal Medicine. McGraw-Hill Education, 2018

23 Lee AH. Pituitary adenoma causing classical migraine. British Journal of Neurosurgery 19904 347-348. (https://doi. org/10.3109/02688699008992746)

24 Akirov A, Masri-Iraqi H, Dotan I \& Shimon I. The biochemica diagnosis of acromegaly. Journal of Clinical Medicine 2021101147. (https://doi.org/10.3390/jcm10051147)

25 Ghazi AA, Amirbaigloo A, Dezfooli AA, Saadat N, Ghazi S, Pourafkari M, Tirgari F, Dhall D, Bannykh S, Melmed S, et al. Ectopic acromegaly due to growth hormone releasing hormone. Endocrine 201343 293-302. (https://doi.org/10.1007/s12020-012-9790-0)

26 Butler PW, Cochran CS, Merino MJ, Nguyen DM, Schrump DS \& Gorden P. Ectopic growth hormone-releasing hormone secretion by a bronchial carcinoid tumor: clinical experience following tumor resection and long-acting octreotide therapy. Pituitary 201215 260-265. (https://doi.org/10.1007/s11102-010-0226-7)

27 Kyriakakis N, Trouillas J, Dang MN, Lynch J, Belchetz P, Korbonits M \& Murray RD. Diagnostic challenges and management of a patient with acromegaly due to ectopic growth hormone-releasing hormone secretion from a bronchial carcinoid tumour. Endocrinology, Diabetes and Metabolism Case Reports 20172017 16-0104. (https://doi. org/10.1530/EDM-16-0104) 